\title{
Study on the Incentive Theory Perspective of Nursing Graduates Employment Destination and Changing Their Job
}

\author{
Wuwei Yin ${ }^{1, a,}{ }^{*}$, Zeli Mao ${ }^{2,}$ \\ ${ }^{1}$ School of Political Science and Public Administration, University of Electronic Science and \\ Technology of China, Chengdu, P.R.China, 611731 \\ ${ }^{2}$ Rehabilitation Medicine, Yichang First People's Hospital, Yichang, P.R.China, 443400 \\ 1768063338@qq.com, \\ * YIN Wu-wei, Male, The Tujia, postgraduate of School of Political Science and Public \\ Administration, Research direction: Education Economy and Management
}

\begin{abstract}
Keywords: Incentive Theory, Nursing Graduates, Changing Jobs, Motivation.
Abstract. These days, employment of nursing graduates has constantly captured wide media attention, occupying the newspapers headlines, with the development of the society, the demand for increased nursing personnel, training of nursing personnel of various schools have been growing. Every coin has two sides, as the economy downward pressure, various malignant doctor-patient and nurse-patient events occur enable we are facing some problems, such as increased nursing personnel, personnel supply and demand irrational structure and other factors will lead the nursing personnel began to changing the road, by actual survey, in-depth analysis of subjective and objective factors, we want to find answers for the nursing graduates changing their job.
\end{abstract}

\section{激励理论视域下的护理专业毕业生就业去向及转行原因研究 \\ 殷武威 ${ }^{1, a}$, , 毛泽丽 ${ }^{2}$, \\ ${ }^{1}$ 电子科技大学政治与公共管理学院, 四川成都, 611731 \\ 2宜昌市第一人民医院康复医学科, 湖北宜昌, 443400 \\ a1768063338@qq.com,}

*殷武威, 男, 1991年出生, 籍贯为湖北宜昌, 土家族, 电子科技大学公共管理硕士生, 研究方向为 现代公共管理，教育经济与管理

关键词：激励理论；护理专业；转行；激励

中文摘要. 护理专业毕业生的就业去向一直是各方关注的焦点, 在本世纪初的经济发展大潮 中护理专业的人才需求量加大, 各种培养护理人才的学校相继壮大, 但是各种恶性医患, 护 患事件的发生使得我们的护理人才所面临的压力加大, 人才供求结构不合理的矛盾凸显等因 素都会使护理人才开始走向转行之路, 本文通过实际调查的方式, 深入分析存在的主客观因 素，力求为护理专业毕业生的转行问题找到答案。

\section{1. 引言}

南丁格尔说: “护士其实就是没有翅膀的天使，是真、善、美的化身。”1980年美国护 理学会将护理定义为: 现代护理学是研究如何诊断和处理人类对存在的或潜在的健康问题反 应的一门科学。 


\section{1 研究对象}

通过对某地的379名已经毕业的护理专业学生进行调查，选取样本标准为：第一，护理专 业毕业生; 第二，距离毕业有一段时间（具体时间为半年以上）; 第三，在被调查者同意的 基础上当场填写并回收。本次调查的被采访者有女性350名, 男性29名, 本科毕业生190名, 专科毕业生179名，实际发放调查表379份，回收360份，回收率94.99\%。

\section{2 调查结果分析}

调查中, 护理专业的毕业生的就业方式趋于多元化, 工作的占到 $75 \%$ 左右, 求学, 自由 职业, 自主创业的越来越多, 但必须清醒的认识到还有一部分处于待业状态。

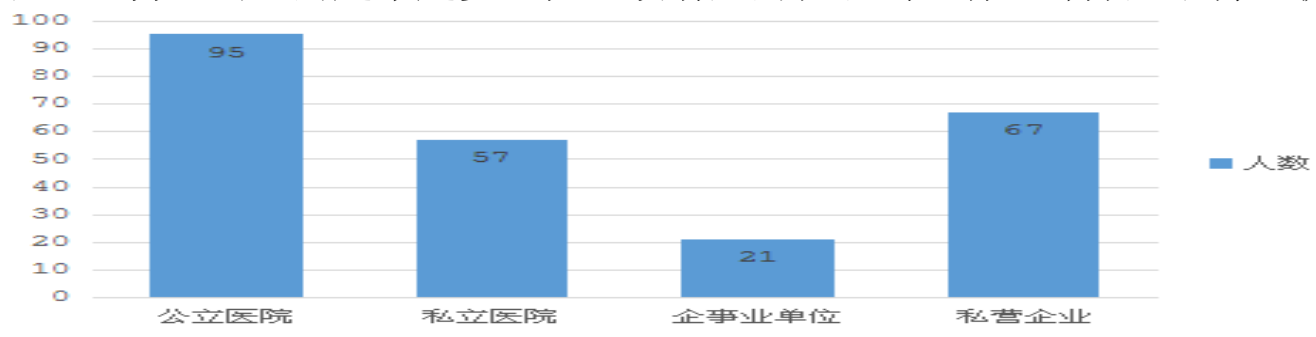

对于工作的毕业生来说, 在公立医院与私立医院工作为主, 企事业单位和私营企业也占 到很大的比例。

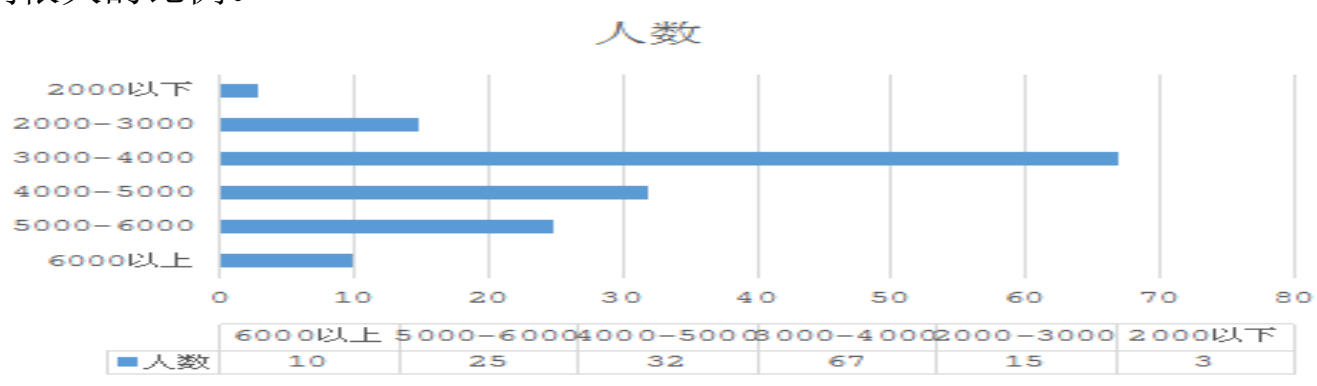

在医院工作的护理专业毕业生普遍的有较合理的收入，3000-4000的比例最大，同时3000 以下的所占比例较小，从客观上说明护理专业的毕业生收入差距不大。

\section{2. 激励理论下的护理专业毕业生转行现状分析}

\section{1 激励理论的概念}

激励理论是关于如何满足人的各种需要、调动人的积极性的原则和方法的概括总结。激 励的目的在于激发人的正确行为动机, 调动人的积极性和创造性, 以充分发挥人的智力效应, 做出最大成绩。

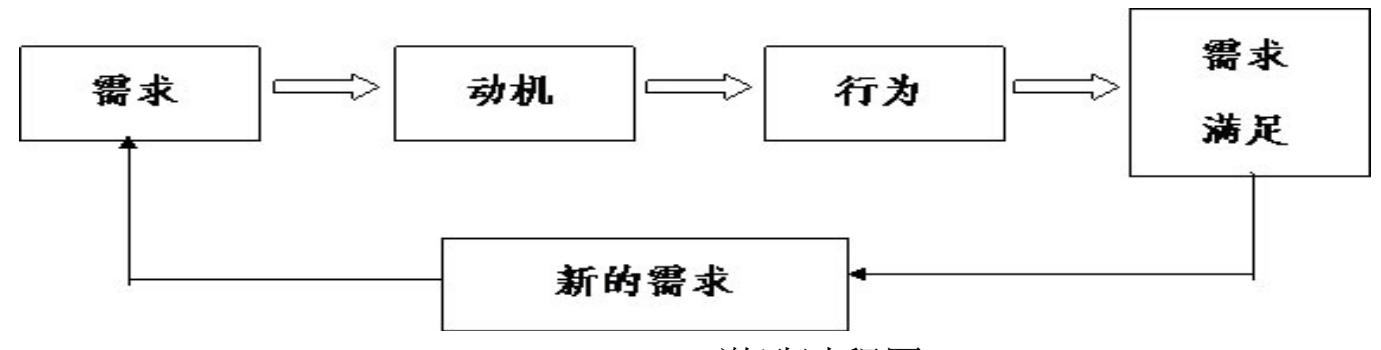

激励过程图

对学习护理专业的学生来说, 从需求开始即满足自己的人生价值与社会价值实现, 社会 价值为帮助病人患者减轻痛苦, 早日康复, 正确执行医嘱, 观察病人的身心状态等方面; 个 人的价值体现在自我价值的体现, 工资福利的回报, 社会的认可度等。以学所所长, 学有所 用, 博学精医为动机, 端正自己的态度, 遵从行业规定, 踏实做事从而实现需求的满足, 继 而朝着新的需求努力, 如此周而复始, 确保护理工作的有序进行。 


\section{2 护理专业毕业生转行的现状分析}

有调查可以得知, 除去求学及自主创业及其他原因的毕业生, 已参加工作的毕业生还是 有 $37 \%$ 左右, 护理专业毕业生所面临的转行危机正在逐步扩大, 具体到影响因素, 国家政策 的支持力度, 社会的多元支持体系的构建, 职业的成就感都会影响原则, 即使是工资福利水 平较其他行业合理，但考虑到社会成员淡漠的眼神，敌视的话语等还是会转投其他行业。

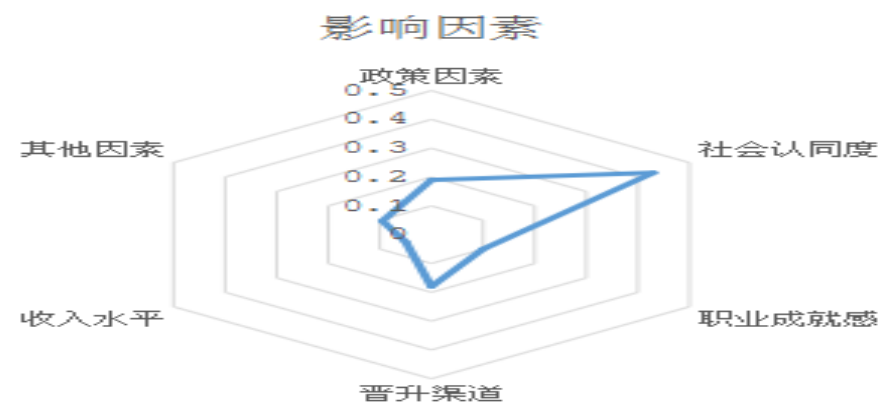

护理专业毕业生转行的影响因素

\section{3. 激励理论视角下的护理专业毕业生转行的原因探究}

\section{1 情绪枯竭与程式化的工作的影响}

3.1.1 工作专业化。护理是一项专业化性很强的工作，但是长期的工作内容，工作方式 的单调运转, 人的情绪就会枯竭, 没有前进或者上升的动力, 因此太过于专业化的工作容易 让护理专业毕业生产生情绪枯竭, 继而想到转行。

3.1 .2 工作程序化。作为护理工作, 洗手有洗手的程序, 消毒有消毒的程序, 换药, 打 针等都有着自己既定的方式, 日常行为更是如此, 护理礼仪, 护理准则时时刻刻在约束监督, 程式化的的工作会引发年轻人的转行行为的发生。

\section{2 社会不认同导致工作成就感低}

3.2.1 医闹事件的不断发生。据中国医院协会的报告显示，2008到2012四年间，发生过 医闹的医院从 $47.7 \%$ 升到 $63.7 \%$, 每年因为医闹事件的损失也在不断上升, 医闹事件的发生 让更多热爱医学的莘莘学子为了自身的安全着想放弃这份职业, 恶性的医闹事件的屡屡发生 促使着越来越多的护理专业毕业生转行。

3.2.2 新媒体时代谣言的控制与扩散。新媒体的到来会使很多未经辨别的消息经过他们 扩散出去, 误导广大的公众, 影响大众对医院, 医护人员的仇视。其次, 谣言一旦产生, 控 制起来就很困难, 国家相关法律法规对谣言的传播具有一定的规定, 但是事件发生后, 法律 才会适用, 法律处置事件滞后性的特点会影响着人们的判断; 第三, 医院自身的公关能力也 是需要考量的方面, 现实是部分医院没有相应的应急预案与联动机制, 在事件发生时, 谣言 产生后，与相关新媒体沟通不够，对事件的控制不足。

3.2.3 社会主体的认识。社会大众的认知对于从事护理专业的工作者来说存在一定的偏 见, 基于传统的认知, 护理就是简单的照顾病人, 技术含量不足, 因此学历必定不高。其次, 部分私立医院的违规, 乱收费, 打着政府的幌子到处宣传圈钱加深了公众的认知误区, 把他 们归为医院的大类进行评价; 再者, 某些医护人员自身的行为违背了医护人员准则, 大众会 把极小众的问题放入医疗行业进行评判, 这些都会让大众对医护人员存在认知上的偏见, 进 而影响到护理专业毕业生的就业选择，也成为了他们转行的原因之一。

\section{3 竞争性机制的缺失, 激励性措施的实施性不够}

3. 3. 1 内部竞争机制不足。护理工作人员的专业性强, 程序化严格, 学习新的知识的周 期长, 因此护理专业的工作人员的流动性较小, 横向, 纵向的对比存在不平等, 第二, 能上 不能下的传统行政机制深深的影响着事业单位, 在资源有限的环境中, 如何合理的配置人力 
资源是需要迫切解决的问题, 仅仅依靠工资福利的刺激对于人才的吸引力不够, 晋升渠道狭 窄，职业成就感降低的原因致使护理专业毕业生选择转行。

3. 3.2 外部竞争机制缺失。外部竞争通常所指的是不同部门，行业的对比，从而得出优 劣势, 逐渐优胜劣汰的过程, 然而缺少有序合理的外部竞争会使相关主体满足于当前所获得 的利益, 逐渐排斥改革, 以消极的差别对待所出现的问题, 专业性的过强导致该行业的替代 性不足, 政府购买的公共服务居于支配地位, 但实际上每个从业人员自身的成就感的满足也 是不健全，有序合理的外部竞争机制的缺失会导致转行现象的出现。

\section{4 国家政策方针的影响}

3.4.1 护理专业的扩招。护理专业的扩招导致护理人才开始泛滥，供求关系改变，供小 于求变成供大于求，人才的增多，行业门槛的提高致使护理专业毕业生被迫转行。

3.4 .2 经济下行压力导致的就业困难。经济的下行压力增大, 各行各业的形势不容乐观, 在经济形式良好的时候就业压力较小, 行业的承载力增大, 当经济处于放缓的时期, 行业对 员工, 人才的吸收量减小, 就业困难产生, 部分毕业生选择转行。

3.4 .3 相关法律法规的不健全。对于医闹事件处罚的法律比较少，《治安处罚条例》《刑 法》对于这类事件的处置都只是笼统的说明, 没有特有法律来规范医闹事件, 没有法律法规 很好保护的护理人才也会被迫转行。

\section{4. 结束语}

护理人才是一种社会专有的人才，工作辛苦，为了患者的恢复勤勤恳恳的工作，但是当 前的护理专业毕业生有很多选择转行, 从事其他的工作, 不是说护理专业人才都不爱惜自己 的专业与工作，而是多方原因导致他们转行，就业困难，社会认同感低，护患，医患事件的 发生，恶性事件的出现等原因都会让他们身心俱疲，从而从事其他行业的工作。为此，我们 的政府应该及时出台相关的法律法规保障医护人员的合法权利，加大宣传力度，让社会更加 了解护理这项工作，同时应该构建社会支持与联动机制，出现医疗事件时及时解决，全社会 共同努力，维护良好的医疗秩序，为护理人员的工作提供确实的保障。

\section{References}

[1] GAO (United States General Accounting Office).Nursing Home Quality:Prevalence of Serious Problems, While Declining, Reinforces Importance of Enhanced Oversight. GAO-03-361 . 2003

[2] Joan Costa-Font,Concepcio Patxot. The Design of the Long-Term Care System in Spain:Policy and Financial Constraints. Social Policy \& Society .

[3] Leners, Debra Woodard,Roehrs, Carol, Piccone.Tracking the Development of Professional Values in Undergraduate Nursing Students. Journal of Nursing . 2006

[4] Lu.A study of the professional commitment changes from nursing students to registered nurses. The Kaohsiung J Med Sci . 2000

[5] Larrabee J H,Bolden L V.Defining patient-perceived quality of nursing care. Journal of Nursing . 2001

[6] Monir Nobahar,Fazlollah Ahmadi,Fatemah Alhani,Masood Fallahi Khoshknab. Working experiences of I ranian retired nurses: A content analysis study[J]. Int J Nurs Pract . 2013 (5) 